\title{
Rolls-Royce Looks Happier
}

THe instability of the economic tightrope which Rolls-Royce has been obliged to walk almost since the start of development of the very successful Spey engines in the early 1960 s has been highlighted during the past week. Rolls-Royce has announced a loss of $£ 48$ million during the first six months of this financial vear, compared with a profit of $£ 2.5$ million last year, and the government has stepped in with massive additional launching aid of $£ 42$ million for the RB 211 turbofan engine. This aid will be supplemented by bank loans of $£ 18$ million and repaid by a levy on sales. Sighs of relief from both sides of the Atlantic that Britain's only acro engine manufacturer has been saved from financial disaster have shown how important Rolls-Royce is in the complex international aerospace web.

The firm's trouble is rooted in the ever escalating costs of the development of the "Dash 22" version of the RB 211 which is to be used in the Lockheed TriStar airbus. The engine contract was plucked from the hands of American competitors in 1968, but the penalty of landing such a prestigious order was a fixed quotation which required more than the average amount of guesswork. As it turned out, estimates for the total development cost have soared from $£ 65$ million in 1968 to $£ 135$ million at 1970 prices, and launching aid of $£ 47$ million granted by the government in 1968 is now seen to be entirely inadequate. A measure of the immediate seriousness of the situation is the provision by Rolls-Royce in its accounts of $£ 45$ million to offset the predicted loss on the 600 engines to be sold to Lockheed during the next five years.

The Rolls-Royce problem is essentially one of cash shortage, the source of which can be traced back to a change of accounting procedure in the early days of the Spey engine. At that time it became impossible to write off research and development totally against profits without depleting the latter to such an extent that the problems of raising further capital in the money market would become insuperable-about $£ 90$ million has been raised by loans and share issues in the last four years alone. The problem was solved by the expedient of charging only a proportion of research and development against profit and entering the remainder as a capital item in the balance sheet, to be written off as profits increased during production. The result was a healthy looking increase in profits from year to year but a hidden strain on cash resources which eventually forced the recent injection of $£ 60$ million.

The Industrial Reorganization Corporation (IRC) made a general loan of $£ 10$ million to Rolls-Royce earlier this year and several new directors were appointed, including Mr Ian Morrow, who now heads the new four man executive committee. It was Mr Morrow's probings and the financial monitoring by the IRC which revealed the company's critical financial situation and gave the government much of the factual information necessary for assessing the aid to be given. Ironically the IRC will be wound up at a time when its usefulness has been highlighted; it would have been the ideal body to watch over the now considerable public investment in Rolls-Royce, and to assess any future requirements for public money which might arise.

In some ways, Rolls-Royce has been shown to suffer from its own tradition of excellence. For example, some 2,000 new parts used to be produced each year as optional extras for existing designs of engine. The IRC investigations revealed too much self confidence and often a refusal to face the economic facts of life. The Rolls-Royce management was, for example, considering a draft contract with Lockheed which specifically promised carbon fibre reinforced fan blades and it was only at the insistence of Lockheed that a back-up programme of research into titanium blades was started. In the event the break-up of carbon fibre blades under adverse conditions, such as heavy rainstorms, made the titanium research vital, even though the extra weight of titanium blades in turn made other design changes necessary.

The Rolls-Royce situation will certainly have a bearing on the choice which the government has to make soon between the European airbus (the A300B) and the British Aircraft Corporation BAC 3-11, both of which are contenders for government support. If the government chose the BAC 3-11 it would saddle itself with two large items of expenditure: $£ 75$ million towards the development of the airframe and about $£ 60$ million for the development of the RB 211-61, an improved and lighter version of the "Dash 22". Even the offer of up to $£ 50$ million from the West German Government does not necessarily make the A300B project more attractive. General Electric, with one foot already in the door, is likely to win a considerable proportion of the engine orders for the United States, thus denying Rolls-Royce the long uninterrupted production run so badly needed and offered by the BAC 3-11 with its estimated sales of at least 280 aircraft (Nature, 228, 496; 1970.)

The plain fact is that a single private firm does not have the boundless capital resources seemingly needed to support the research and development functions necessary in the aerospace industry, or the resilience to survive unaided the inevitable setbacks. It can be argued that Rolls-Royce channels too little of its effort (about 20 per cent) into bread-and-butter products such as marine engines, but although the non-aero side of the business is expanding well, it could never provide the degree of cushioning required. The continuing injection of government money and the appointment of watchdog directors are probably too close to nationalization to be contemplated by the government, although the aerospace industry in the United States is subsidized extensively and successfully in the guise of defence grants.

It has been suggested that the next logical step would be the formation of a European company with RollsRoyce as its nucleus and comprising firms like the French SNECMA and Turbomeca and the West German group Motoren und Turbinen Union which are all intimately involved with Rolls-Royce in one or other of the joint ventures. 